\title{
Annual cycle of benthic nutrient fluxes in Tomales Bay, California, and contribution of the benthos to total ecosystem metabolism*
}

\author{
S. J. Dollar ${ }^{1}$, S. V. Smith ${ }^{2}$, S. M. Vink ${ }^{2}$, S. Obrebski ${ }^{3}$, J. T. Hollibaugh ${ }^{3}$ \\ ${ }^{1}$ Hawaii Institute of Marine Biology, University of Hawaii, Honolulu, Hawaii 96822, USA \\ ${ }^{2}$ Department of Oceanography, University of Hawaii, Honolulu, Hawaii 96822, USA \\ ${ }^{3}$ Tiburon Center, San Francisco State University, Tiburon, California 94920, USA
}

\begin{abstract}
Benthic fluxes of dissolved nutrients, oxygen, dissolved inorganic carbon, and total alkalinity were measured over a $2 \mathrm{yr}$ period in Tomales Bay, California, USA, using in situ incubation chambers. Release of dissolved nutrients from the sediment peaked in late summer and was lowest in winter. The difference between $\mathrm{C}: \mathrm{N}$ : $\mathrm{P}$ flux ratios and composition of suspended particulates indicated the existence of a sink for regenerated $N$, relative to $C$ and $P$. Total alkalinity flux revealed that carbon metabolism by net sulfate reduction represented ca one-third of total benthic metabolism. Partitioning net system fluxes into component fluxes suggested that the equivalent of ca 70 to $80 \%$ of the available particulate $\mathrm{C}, \mathrm{N}$ and $\mathrm{P}$ was respired within the water column, while about 20 to $30 \%$ was respired by the benthos. During spring, increasing light resulted in higher water column productivity, followed closely by rising water column respiration. With low delivery of the new organic material to the benthos, and low residual organics in the sediment, benthic respiration remained low. Fallout of particulate material, coinciding with peak water temperature in late summer, resulted in a 'crossover' with benthic respiration temporarily exceeding water column respiration.
\end{abstract}

\section{INTRODUCTION}

In estuaries and shallow coastal marine environments, benthic fluxes of dissolved materials play an important role in biogeochemical cycling. For instance, nutrients released by benthic processes have been shown to supply a significant fraction of the requirements of primary producers in the overlying water (e.g. Hale 1975, Nixon 1981, Bulleid 1984, Boynton \& Kemp 1985, Rizzo 1990). The sediment can also serve as a sink for nutrients; denitrification in sediments can result in a deficit of dissolved nitrogen flux to the water column relative to phosphorus flux (Seitzinger et al. 1980, 1984, Nixon 1981). There is also evidence that there may be a general relationship between rates of delivery of organic materials to the sediment surface and benthic flux throughout the range of coastal marine environments (Nixon 1981).

\footnotetext{
- Contribution no. 2692 of the School of Ocean and Earth Science and Technology
}

While there is an abundant literature describing the results of in situ measurements of benthic fluxes, most of these studies have been relatively limited in duration, particularly in terms of repetitive sampling over entire annual cycles. As a result, there is a relatively limited data set that depicts patterns of seasonal variation of benthic fluxes. It follows that there is limited interpretation of the effect that varying environmental parameters associated with weather may have on patterns of benthic flux.

Tomales Bay, a temperate-climate estuary located in northern California, USA, has been the site of an intensive research effort to examine the biogeochemical coupling at the land-sea interface (LSI) (see Hollibaugh et al. 1988). Tomales Bay presents an ideal setting for such a program because it is at once amenable to studies of net transformations within the LSI, and at the same time accessible for more conventional analyses of the processes and material cycles responsible for the net transformations. Benthic fluxes of dissolved materials $(\mathrm{C}, \mathrm{O}, \mathrm{N}, \mathrm{P}$, and $\mathrm{Si})$, along with water column primary productivity, have been measured approxi- 
mately every 2 mo since June 1987. This paper reports the results of the first 2 years of these continuing investigations.

In addition to examining the pattern of benthic flux, we are also interested in understanding the contribution of benthic flux to the net ecosystem metabolism of Tomales Bay. Individual component fluxes, measured in relative isolation from the remaining components, can be summed to yield an indication of net system function (e.g. Atkinson \& Grigg 1984, Hopkinson 1985, Rowe et al. 1986). It must be cautioned, however, that net metabolic estimates derived by such summation are limited by the precision and accuracy of the methodologies of measuring individual, inherently 'noisy' fluxes. Such a problem is especially relevant in determining a valid production-to-respiration ratio when net production is near zero.

System-level metabolic budgets, which are not compromised by the precision of several independent component measurements, have also been calculated for Tomales Bay. These budgets are the result of solutions of hydrographic and stoichiometric equations that describe nutrient dynamics in the bay (Smith et al. 1987, 1989, 1991). Using the measured component fluxes and net system fluxes, we can solve for the sum of components not directly measured and then evaluate how the various component fluxes are constrained to contribute to the net system function.

\section{STUDY SITE}

Hydrographic and biotic descriptions of Tomales Bay are presented in Smith et al. (1987) and Hollibaugh et al. (1988). Located ca $50 \mathrm{~km}$ north of San Francisco, Tomales Bay occupies a rift valley formed by the San Andreas fault (Fig. 1). The bay forms a long $(20 \mathrm{~km})$, narrow $(1.4 \mathrm{~km})$ estuary with an average depth of $3.1 \mathrm{~m}\left(z_{\max }=19 \mathrm{~m}\right)$. About $30 \%$ of the area is shallower than $2 \mathrm{~m}$, with shoals near the mouth, the head, and the northeast shoreline. Outer bay ( 0 to $8 \mathrm{~km}$ from the mouth) sediments are predominantly sand and sandy muds. Inner bay ( 8 to $20 \mathrm{~km}$ from the mouth) sediments are composed of fine muds containing abundant epi- and infauna. Eelgrass beds occur in the bay, predominantly near the mouth and along the northeastern shore. Dense growths of macroalgae appear in summer in the most landward areas of the bay (ca 14 to $20 \mathrm{~km}$ from the mouth).

\section{METHODS}

Benthic fluxes. Benthic fluxes were measured 12 times between June 1987 and May 1989 at sites corresponding to bay transect Stns 6,10 and 16 (Fig. 1).

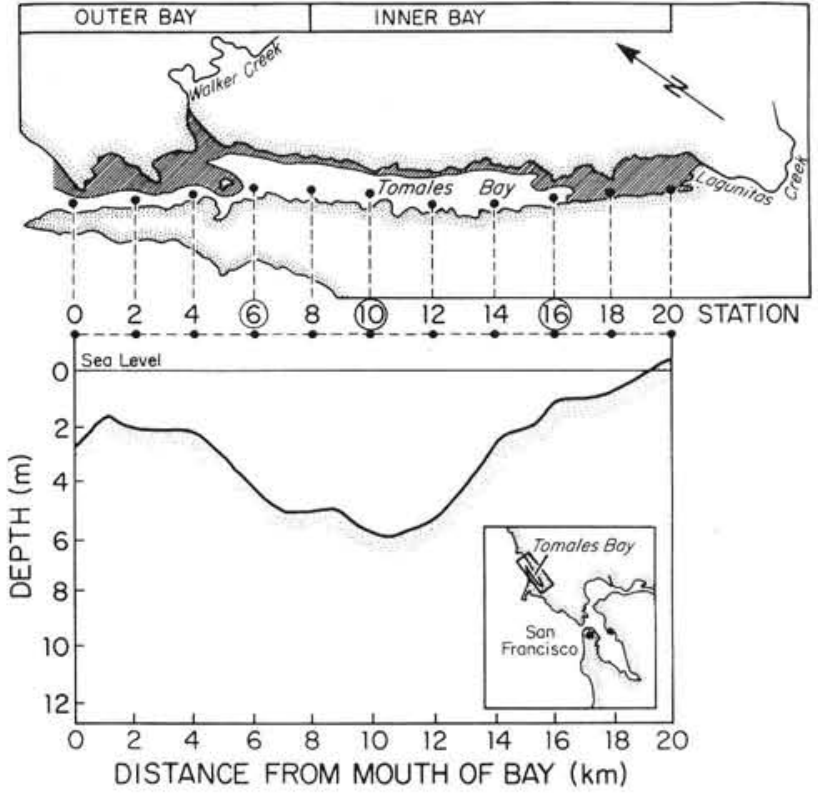

Fig. 1. Tomales Bay in northern California. Benthic flux sampling stations located ca 6,10 , and $16 \mathrm{~km}$ from the mouth of the bay are circled

Fluxes at each site were determined using 3 to 6 transparent plexiglass hemispherical domes $50 \mathrm{~cm}$ in diameter. A vertical skirt $15 \mathrm{~cm}$ deep, and horizontal equatorial flange $10 \mathrm{~cm}$ wide, limited penetration of the bottom edge of the dome. Lead weights attached to the flange assisted in anchoring each dome. Batterypowered stirrers adapted from YSI oxygen electrodes attached to the inner surface of each dome prevented water stagnation. The area of sediment covered by a dome was $0.2 \mathrm{~m}^{2}$, and the enclosed volume was $33 \mathrm{l}$.

At all stations, incubations were conducted in water depths of 4 to $6 \mathrm{~m}$. At each deployment, domes were placed into the sediment one at a time by SCUBA divers working from a boat. Two PVC stopcocks in each dome were left open so that ambient water could flush the interior space. After $30 \mathrm{~min}$, a $300 \mathrm{ml}$ initial water sample was withdrawn from each dome through one stopcock into two $150 \mathrm{ml}$ plastic syringes. During sampling, a second stopcock remained open to assure replacement of the sample volume with ambient bay water rather than sediment interstitial water. Subsequent studies have demonstrated that ambient concentrations in the water column are similar to the initial concentrations in the domes.

After ca $24 \mathrm{~h}$ a second $300 \mathrm{ml}$ sample was withdrawn. During the initial 4 sampling periods (June to December 1987), an intermediate sample was withdrawn after ca 8 to $10 \mathrm{~h}$ of incubation. Results of the intermediate samplings indicated that changes in concentrations were constant in time; short-term measurements of water composition yielded some changes near 
detection limits. Hence, only the endpoints were measured in subsequent samplings.

Immediately after collection, water samples were analyzed for dissolved oxygen and temperature using a YSI digital oxygen meter. Measurements of $\mathrm{pH}$ were made with a high impedance digital electrometer and combination electrode within $3 \mathrm{~h}$ of sample collection. Alkalinity samples were immediately filtered into polyethylene bottles and measured within $2 \mathrm{~d}$ of collection $(\mathrm{pH}$ and alkalinity procedure reported in detail by Smith et al. 1991). Alkalinity flux was corrected for flux associated with nutrients (primarily $\mathrm{NH}_{4}{ }^{+}$). Total alkalinity and $\mathrm{pH}$ were used to calculate dissolved inorganic carbon (DIC).

Nutrient samples were filtered in the field through GFC filters into $\mathrm{HCl}$-washed, sample-rinsed $(3 \times)$ polyethylene bottles, immediately placed on ice, and frozen within $3 \mathrm{~h}$. Samples were returned frozen to the University of Hawaii, where analyses were performed on a Technicon AAII system, with standard procedures modified for high-precision analyses (Technicon Industrial Systems 1973).

Benthic flux $(J)$ per unit area of bay floor was calculated using the equation:

$$
J=V\left(C_{t}-C_{0}\right) /(A T)
$$

where $V=$ volume of water enclosed within the incubation chamber over the sediment; $C_{0}$ and $C_{t}=$ dissolved concentrations before and after time $T_{i}$ and $A$ = sediment area enclosed. During the initial 4 sampling periods (June through December 1987), a control dome with a closed bottom was used along with 5 sample domes. Because fluxes measured in domes with closed bottoms were very low and erratic compared to benthic fluxes, the control dome was eliminated. For the subsequent 4 periods, 6 sample domes were used. From November 1988 through May 1989, 3 sample domes were used. In total (including some aborted deployments, lost samples, or clearly erroneous measurements), data for 169 incubations were available.

Primary productivity. Phytoplankton primary productivity was estimated during each sampling period from June 1987 to May 1989 (with the exception of August 1987) using a regression algorithm derived for Tomales Bay (Cole 1989). The output of the algorithm is vertically integrated net primary production $\left(\mathrm{mg} \mathrm{C} \mathrm{m}^{-2}\right.$ $\mathrm{d}^{-1}$ ). Samples were collected for chlorophyll concentration, and secchi disk depth was measured along the length of the bay, usually at $2 \mathrm{~km}$ increments. One liter of surface water was filtered through GFC filters and analyzed for chlorophyll concentration using standard methods (Parsons et al. 1984). Daily irradiance data were obtained from weather stations at either end of Tomales Bay.

\section{RESULTS}

\section{Determination of bay-wide benthic fluxes}

Table 1 summarizes mean benthic fluxes for each of the 3 sampling sites, as well as for pooled sites (entire bay). Percent standard deviation (s.d./mean $\times 100$ ) was high for all fluxes, but especially for dissolved organic nitrogen (DON), dissolved organic phosphorus (DOP) and $\mathrm{NO}_{3}{ }^{-}$. Inspection of the data revealed that the standard deviations for DON and DOP were greatly influenced by 5 samples measured in August of 1987 at Stn 10. Calculating the mean DOP flux without these 5 samples reduced the mean flux from -0.18 to $-0.003 \mathrm{mmol} \mathrm{m}^{-2} \mathrm{~d}^{-1}(\mathrm{n}=163)$, while the percent standard deviation changed from 0.1 to 0.003 . The mean DOP flux for the data set without the outliers was about $1 \%$ of the dissolved inorganic phosphorus (DIP) flux. Similarly, mean DON flux changed from -1.22 to $-0.30 \mathrm{mmol} \mathrm{m} \mathrm{m}^{-1} \mathrm{~d}^{-1}$ with the elimination of the same 5 outliers, while the percent standard deviation was reduced from 0.6 to 0.07 . With the reduced data set, mean DON flux was about $15 \%$ of dissolved inorganic nitrogen (DIN) flux. $\mathrm{NO}_{3}{ }^{-}$flux was a trivial fraction of DIN flux, so the high proportional error of $\mathrm{NO}_{3}{ }^{-}$poses no particular problems of interpretation.

In order to make comparisons between calculated system-level fluxes and measured component fluxes, it is advantageous to consider the bay as a single system, rather than as several distinct subzones with different metabolic properties. If the entire bay is functioning as a homogeneous system, measured fluxes from the 3 sampling sites could be pooled to characterize the flux for the entire bay at any one sampling time. A nested ANOVA was used to establish if temporal and error components contribute more to variation than among-station components. In the ANOVA the groupings were Months within Seasons within Years within Stations. Significance testing was performed using the SAS procedure GLM model (SAS Institute 1988) on log-transformed variables:

Variable $=$ Station + Year $($ Station $)+$ Season $($ Year, Station) + Month (Season, Year, Station)

The SAS procedure NESTED was used to obtain the variance components. Results of the analysis (Table 2) showed that Error was usually the largest component of variation, followed by the Season variance component. These results support the assumption that for the purpose of evaluating benthic metabolism, the bay can be viewed as a homogeneous system.

In order to characterize temporal variation, a periodic regression analysis was also performed on all benthic flux data. We assumed that there was an underlying annual periodicity in the fluxes. The periodic regression used was of the form:

$$
Y=\operatorname{Int}+a(X)+b(Z)
$$


Table 1. Benthic fluxes measured in Tomales Bay, California. All fluxes are in mmol m $\mathrm{m}^{-2} \mathrm{~d}^{-1}$, except TA, which is in meq $\mathrm{m}^{-2} \mathrm{~d}^{-1}$

\begin{tabular}{|c|c|c|c|c|c|c|c|c|c|c|c|}
\hline Stn & & $\mathrm{O}_{2}$ & DIC & TA & $\mathrm{NH}_{4}$ & $\mathrm{NO}_{3}$ & DIN & DON & $\mathrm{PO}_{4}$ & DOP & $\mathrm{Si}$ \\
\hline \multirow[t]{4}{*}{6} & Mean & -14.97 & 21.69 & 3.80 & 1.87 & -0.10 & 1.77 & -0.21 & 0.19 & -0.01 & 4.70 \\
\hline & s.d. & 9.56 & 16.45 & 5.34 & 1.35 & 0.23 & 1.40 & 0.63 & 0.17 & 0.03 & 3.28 \\
\hline & s.e. & 1.21 & 2.11 & 0.68 & 0.17 & 0.03 & 0.18 & 0.08 & 0.02 & 0.00 & 0.42 \\
\hline & $\mathrm{n}$ & 62 & 61 & 61 & 61 & 62 & 61 & 61 & 61 & 61 & 61 \\
\hline \multirow[t]{4}{*}{10} & Mean & -8.64 & 25.98 & 11.64 & 2.81 & 0.06 & 2.87 & -3.47 & 0.41 & -0.57 & 4.65 \\
\hline & s.d. & 13.88 & 33.12 & 25.01 & 3.52 & 0.10 & 3.52 & 13.22 & 0.63 & 2.45 & 3.90 \\
\hline & s.e. & 1.89 & 4.51 & 3.40 & 0.48 & 0.01 & 0.48 & 1.80 & 0.09 & 0.34 & 0.53 \\
\hline & $\mathrm{n}$ & 54 & 54 & 54 & 54 & 54 & 54 & 54 & 53 & 53 & 54 \\
\hline \multirow[t]{4}{*}{16} & Mean & -3.68 & 14.41 & 5.74 & 1.22 & 0.02 & 1.24 & -0.08 & 0.13 & 0.01 & 1.38 \\
\hline & s.d. & 11.57 & 20.36 & 14.07 & 1.54 & 0.07 & 1.57 & 0.64 & 0.20 & 0.06 & 1.60 \\
\hline & s.e. & 1.57 & 2.77 & 1.91 & 0.21 & 0.01 & 0.21 & 0.09 & 0.03 & 0.01 & 0.22 \\
\hline & $\mathrm{n}$ & 54 & 54 & 54 & 54 & 54 & 54 & 53 & 54 & 54 & 54 \\
\hline \multirow[t]{4}{*}{ All bay } & Mean & -9.37 & 20.73 & 6.92 & 1.96 & -0.01 & 1.95 & -1.22 & 0.24 & -0.18 & 3.63 \\
\hline & s.d. & 12.55 & 24.40 & 16.76 & 2.39 & 0.17 & 2.42 & 7.63 & 0.40 & 1.39 & 3.44 \\
\hline & s.e. & 0.96 & 1.88 & 1.29 & 0.18 & 0.01 & 0.19 & 0.59 & 0.03 & 0.11 & 0.26 \\
\hline & $\mathrm{n}$ & 170 & 169 & 169 & 169 & 170 & 169 & 168 & 168 & 168 & 169 \\
\hline \multirow{4}{*}{\multicolumn{2}{|c|}{$\begin{array}{c}\text { All bay }^{\text {a }} \text { Mean } \\
\text { s.d. } \\
\text { s.e. } \\
\text { n }\end{array}$}} & & & & & & & 0.30 & & -0.003 & \\
\hline & & & & & & & & 0.93 & & 0.05 & \\
\hline & & & & & & & & 0.07 & & 0.00 & \\
\hline & & & & & & & & 163 & & 163 & \\
\hline
\end{tabular}

Table 2. Results of nested ANOVA. Values are percentages of variation attributable to the components obtained using the SAS NESTED procedure. The levels of significance of $\mathrm{R}^{2}$ values refer to the results of the model fitting using the GLM procedure

\begin{tabular}{|c|c|c|c|c|c|c|c|c|c|}
\hline Component & $\mathrm{O}_{2}$ & DIC & TA & $\mathrm{NH}_{4}$ & $\mathrm{NO}_{3}$ & DON & $\mathrm{PO}_{4}$ & DOP & $\mathrm{Si}$ \\
\hline Station & 9.49 & 2.97 & 2.03 & 0.00 & 10.52 & 0.00 & 0.87 & 0.00 & 19.96 \\
\hline Year & 0.00 & 0.24 & 0.00 & 12.05 & 0.00 & 0.36 & 0.00 & 0.20 & 2.61 \\
\hline Season & 38.88 & 38.93 & 25.99 & 0.11 & 42.77 & 21.24 & 35.86 & 22.79 & 32.25 \\
\hline Month & 0.00 & 4.57 & 0.00 & 60.87 & 0.00 & 0.00 & 0.00 & 0.00 & 11.76 \\
\hline Error & 51.63 & 53.30 & 71.98 & 26.97 & 46.71 & 78.40 & 63.27 & 77.01 & 33.42 \\
\hline $\mathrm{R}^{2}$ & $0.51 \cdots$ & $0.57^{\cdots}$ & $0.39 \cdots$ & $0.78^{\cdots} \bullet$ & $0.52 \cdots$ & $0.23 \mathrm{~ns}$ & $0.38 \cdots$ & $0.24 \mathrm{~ns}$ & $0.71 \cdots$ \\
\hline
\end{tabular}

where Int $=$ the intercept; $a$ and $b$ are coefficients; $X=$ $\cos (C T) ; Z=\sin (C T) ; T=$ time (in months from January 1987 ); $C=2 \pi / K$ radians; and $K=$ the period, in this case 12 . The semi-amplitude of the sine curve is given by $\left(a^{2}+b^{2}\right)^{1 / 2}$. The flux curves in Fig. 2 show peak rates in late summer, and lowest rates in winter. Most of the extreme fluxes occurred at Stn 10, located in the middle of the bay.

\section{Stoichiometric considerations of nutrient fluxes}

Examination of the nutrient ratios of benthic fluxes provides an indication of the source material for sediment respiration and the nature of metabolic processes occurring in the sediment. Slopes of geometric mean regression equations indicated that molar DIN : DIP and DIC:DIN benthic flux ratios were 6 and 12, respectively (Fig. 3). Corresponding suspended load ratios were 15 and 7, very near the Redfield ratio. Thus, the benthic $\mathrm{N}$ flux was $60 \%$ below that which would be expected based on $\mathrm{P}$, and $42 \%$ below that expected based on $C$. The differences between the ratios of benthic fluxes and local Redfield ratios implied that if material respired by the benthic community is predominantly suspended material, there is a sink for regenerated $\mathrm{N}$, relative to $\mathrm{C}$ and $\mathrm{P}$ regeneration. Based on $\mathrm{C}: \mathrm{N}$ ratios in excess of $10: 1$, the excess $N$ was not preserved in the sediments (Smith et al. 1987, unpubl.). Compared to $\mathrm{N}: \mathrm{P}$ and $\mathrm{C}: \mathrm{N}$, the DIC:DIP ratio of benthic flux (82) and the Redfield C: $\mathrm{P}$ ratio (106) were within $23 \%$ of expectation, generally corroborating the 
assumption that benthic respiration is fueled predominantly by planktonic material. Moreover, the high correlation between DIP flux and both DIC and DIN flux suggests that the predominant $\mathrm{P}$ source is organic matter, rather than a mineral phase.

We interpret the discrepancy between substrate composition and regenerative fluxes of nitrogen to have been the result of denitrification in the sediments and at the sediment-water interface. DON and DOP fluxes were near zero, so they are ignored in this analysis. The magnitude of sediment denitrification (SD) can be estimated using the stoichiometric relationship:

$$
\mathrm{SD}=\left[(\mathrm{N} / \mathrm{P})_{\mathrm{e}} \times \mathrm{P}_{\mathrm{f}}\right]-\mathrm{N}_{\mathrm{f}}
$$

where $(\mathrm{N} / \mathrm{P})_{e}=$ the expected N/P ratio based on local Redfield material; and $\mathrm{P}_{\mathrm{f}}$ and $\mathrm{N}_{\mathrm{f}}=$ measured $\mathrm{P}$ and $\mathrm{N}$ benthic fluxes, respectively. Solving Eq. (1) using the
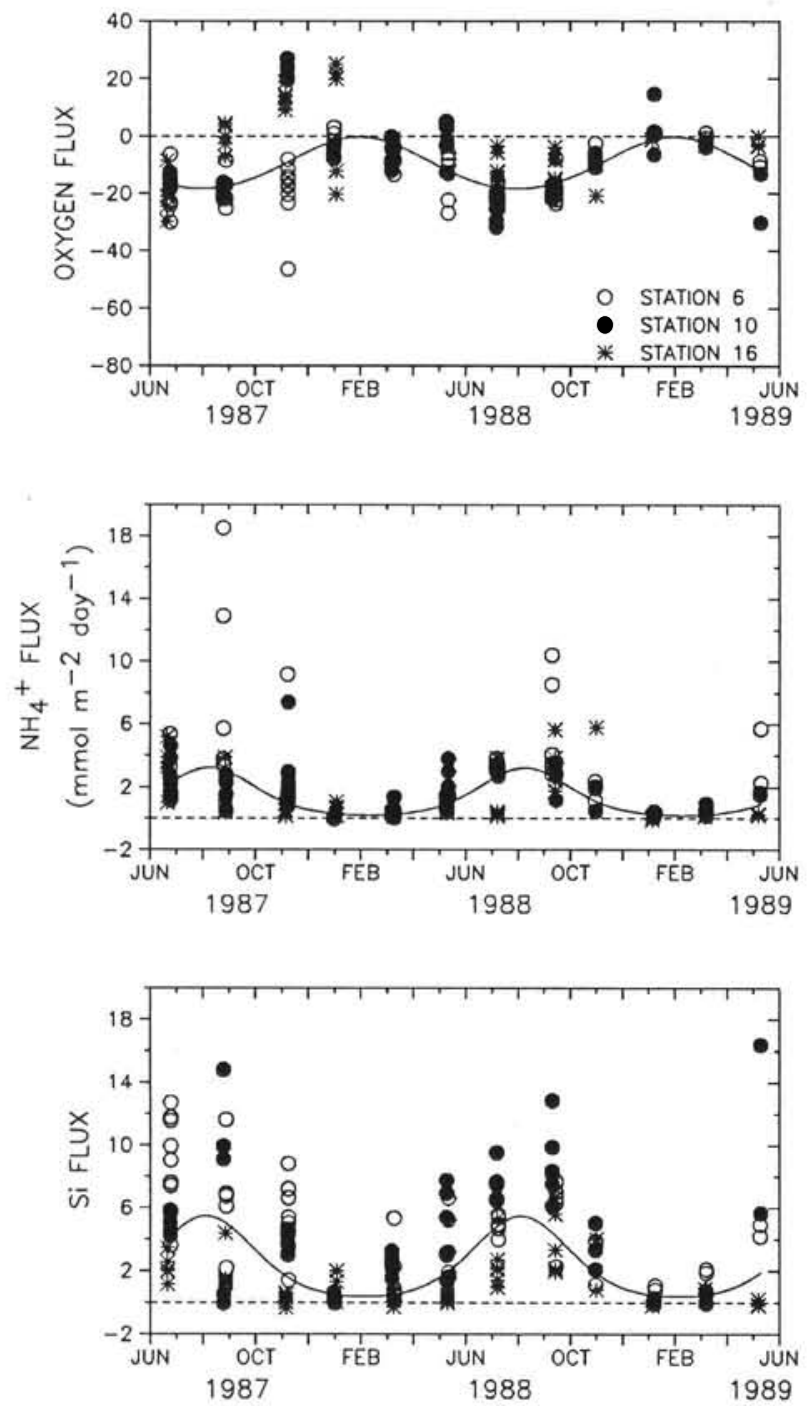

mean annual benthic fluxes of DIP and DIN, mean SD in Tomales Bay was $1.3 \mathrm{mmol} \mathrm{N} \mathrm{m} \mathrm{N}^{-2} \mathrm{~d}^{-1}$.

An equivalent stoichiometric argument can be made utilizing the expected N/C ratio and measured DIC flux. In this case:

$$
\mathrm{SD}=\left[(\mathrm{N} / \mathrm{C})_{\mathrm{e}} \times \mathrm{C}_{\mathrm{f}}\right]-\mathrm{N}_{\mathrm{f}}
$$

On a bay-wide average, SD based on N/C flux ratios equaled $1.2 \mathrm{mmol} \mathrm{N} \mathrm{m}^{-2} \mathrm{~d}^{-1}$.

These 2 approaches for estimating benthic denitrification, one based on N:P stoichiometry and one based on $\mathrm{C}: \mathrm{N}$ stoichiometry, suggested that about $1.25 \mathrm{mmol}$ $\mathrm{N} \mathrm{m}^{-2} \mathrm{~d}^{-1}$ was lost to $\mathrm{N}_{2}$ gas.

\section{Annual mean fluxes of nutrients}

Measurements over the 24 mo of sampling were combined to provide a bay-wide value over an 'average' annual period. In order to evaluate the relationship between benthic flux and water temperature, mean temperature for each day of the year was calculated based on data collected by 6 recording thermographs at 4 locations along the axis of Tomales Bay. The temperature records span the same duration as the benthic flux measurements.

Plots of both mean daily temperatures and bay-wide benthic fluxes are shown in Fig. 4. Denitrification
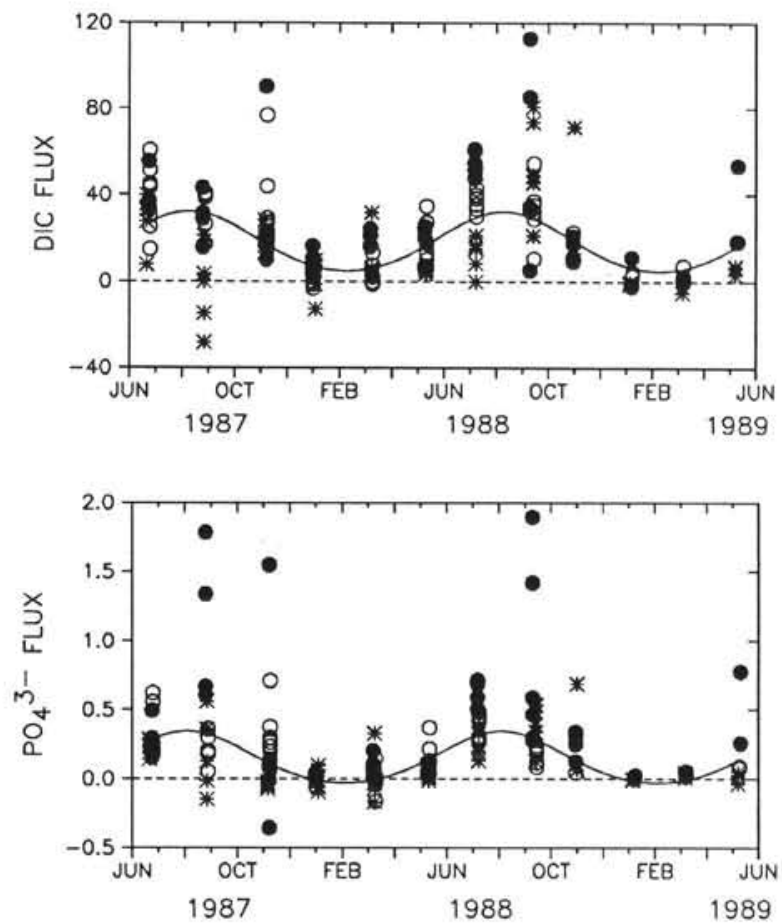

Fig. 2. Benthic fluxes for individual incubations at 3 stations in Tomales Bay for 12 sampling intervals between June 1987 and May 1989. Positive fluxes indicate release by the sediment to the water column; negative fluxes indicate uptake by the sediment. The continuous line represents the periodic regression curve for combined flux data from all stations. All fluxes are in mmol $\mathrm{m}^{-2} \mathrm{~d}^{-1}$ 
fluxes (Fig. 4) were calculated using both Eqs. (1) \& (2). Carbon metabolism via sulfate reduction (Fig. 4) was equivalent to the nutrient-corrected total alkalinity (TA) flux. It is evident that the pattern of benthic flux followed temperature to the extent that peak flux coincided with peak temperature in August/September. It is also evident that the relationship between rising temperature and benthic flux was not linear; in all of the plots shown in Fig. 4, the benthic flux curves described an upward concave shape during winter-
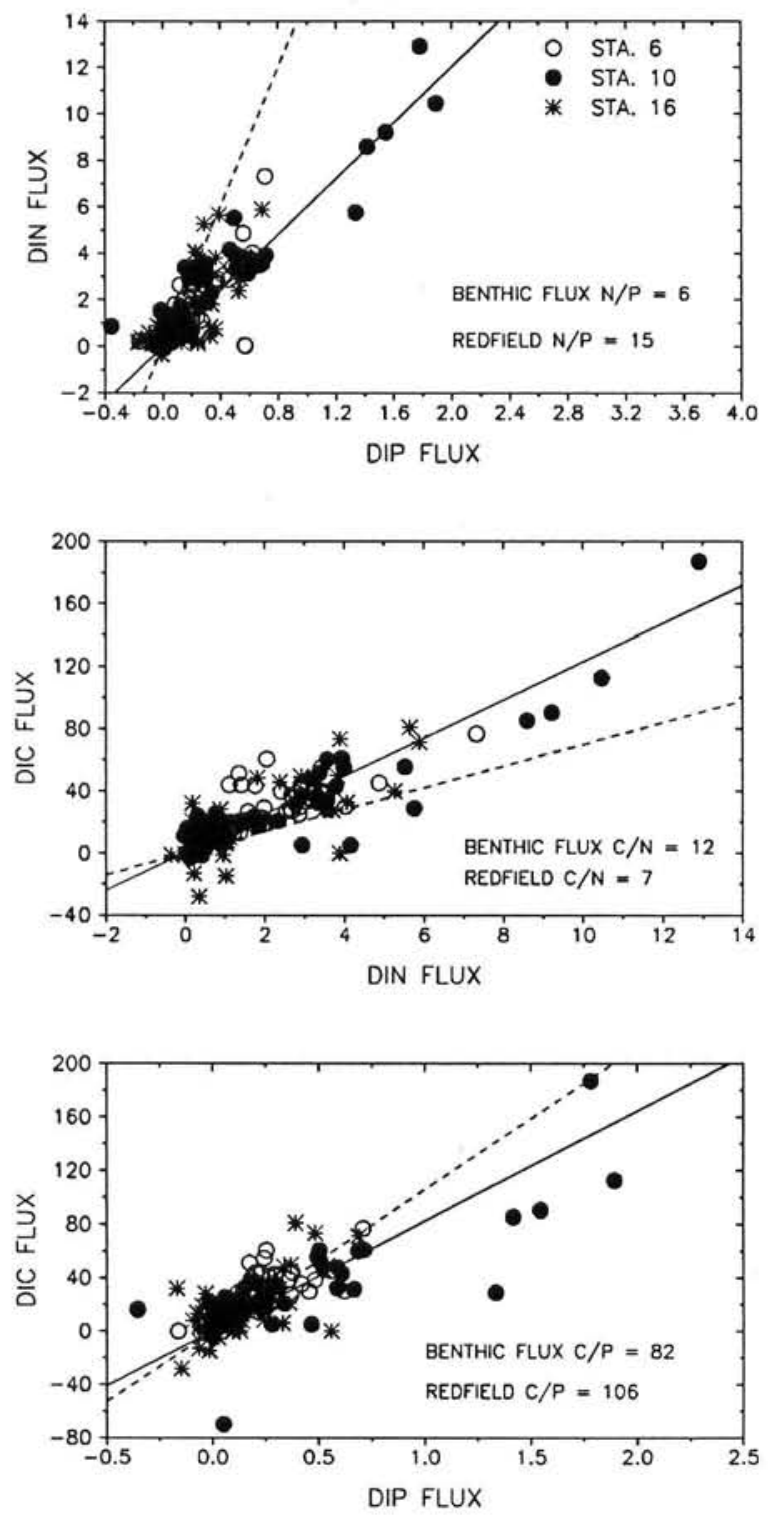

Fig. 3. Benthic fluxes of DIN vs DIP, DIC vs DIN, and DIC vs DIP at 3 sampling stations in Tomales Bay. Dashed lines represent 'local Redfield' ratios, which are the $\mathrm{C}: \mathrm{N}$ : $\mathrm{P}$ ratios of suspended material in the water column. The slope of the linear regression lines (continuous lines) for the individual flux measurements represents the ratio of benthic fluxes. All fluxes are in $\mathrm{mmol} \mathrm{m}^{-2} \mathrm{~d}^{-1}$ spring that was not evident in fall. In contrast, the seasonal rise of temperature was convex upward. On the other hand, the relationship between these variables as temperature fell, did appear more linear.

Fig. 5 shows daily means of irradiance (collected at 2 weather stations on Tomales Bay), and measured baywide means of water column primary productivity. Peak light occurred in June, while peak primary productivity followed in July. The symmetry of these patterns is distinctly different from that of the temperature vs benthic flux plots shown in Fig. 4.

\section{Calculated component fluxes}

Annual net non-conservative fluxes (NF), derived from hydrographic and stoichiometric models, are presented in Smith et al. (1991). In that study, no clear pattern of seasonal variation in net system metabolism emerged, so constant values over the year are assumed. We assume that NF is a result of respiration $(R)$ minus production $(P)$ for both the benthic $(\mathrm{b})$ and water column $(\mathrm{w})$ components. Therefore,

$$
\mathrm{NF}=\left(R_{\mathrm{b}}-P_{\mathrm{b}}\right)+\left(R_{\mathrm{w}}-P_{\mathrm{w}}\right)
$$

Benthic respiration $\left(R_{\mathrm{b}}\right)$ and water column primary production $\left(P_{\mathrm{w}}\right)$ were directly estimated components of the Tomales Bay system. While benthic production $\left(P_{\mathrm{b}}\right)$ was not measured as a component flux, it can be estimated. Seagrass beds cover ca $1 \mathrm{~km}^{2}$ of the $18 \mathrm{~km}^{2}$ of the inner bay region which is assessed by the total system flux calculations. Smith et al. (1991) estimate that benthic primary productivity may equal about $25 \%$ of plankton productivity, and the $\mathrm{C}: \mathrm{N}: \mathrm{P}$ ratio of benthic plants is about 550:30:1 (Atkinson \& Smith 1983), so that:

$$
\mathrm{NF}=\left(R_{\mathrm{b}}-0.25 P_{\mathrm{w}}\right)+\left(R_{\mathrm{w}}-P_{\mathrm{w}}\right)
$$

Substituting the annual means of NF, $R_{\mathrm{b}}$, and $P_{\mathrm{w}}$, we can solve Eq. (4) for $R_{\mathrm{w}}$ in terms of DIC, DIN and DIP fluxes.

For DIC flux in Tomales Bay, NF equals about $10 \mathrm{mmol}$ $\mathrm{m}^{-2} \mathrm{~d}^{-1}$, and seasonally averaged $P_{\mathrm{w}}$ is about $60 \mathrm{mmol}$ $\mathrm{m}^{-2}$ (Smith etal. 1991). $R_{\mathrm{b}}$ equals about $21 \mathrm{mmolm}^{-2} \mathrm{~d}^{-1}$. Solving Eq. (4), $R_{\mathrm{w}}$ is about $64 \mathrm{mmol} \mathrm{m}^{-2} \mathrm{~d}^{-1}$. Thus, on an annual basis, the equivalent of ca $75 \%$ of the $\mathrm{C}$ fixed in the system is respired within the water column, and $25 \%$ by the sediment community. Similar partitioning shows that about $70 \%$ of DIP flux is a result of water column respiration, compared to $80 \%$ of DIN flux.

\section{DISCUSSION}

\section{Validity of benthic flux measurements}

A criticism of in situ incubations is that reduction in oxygen concentration owing to the experimental enclo- 

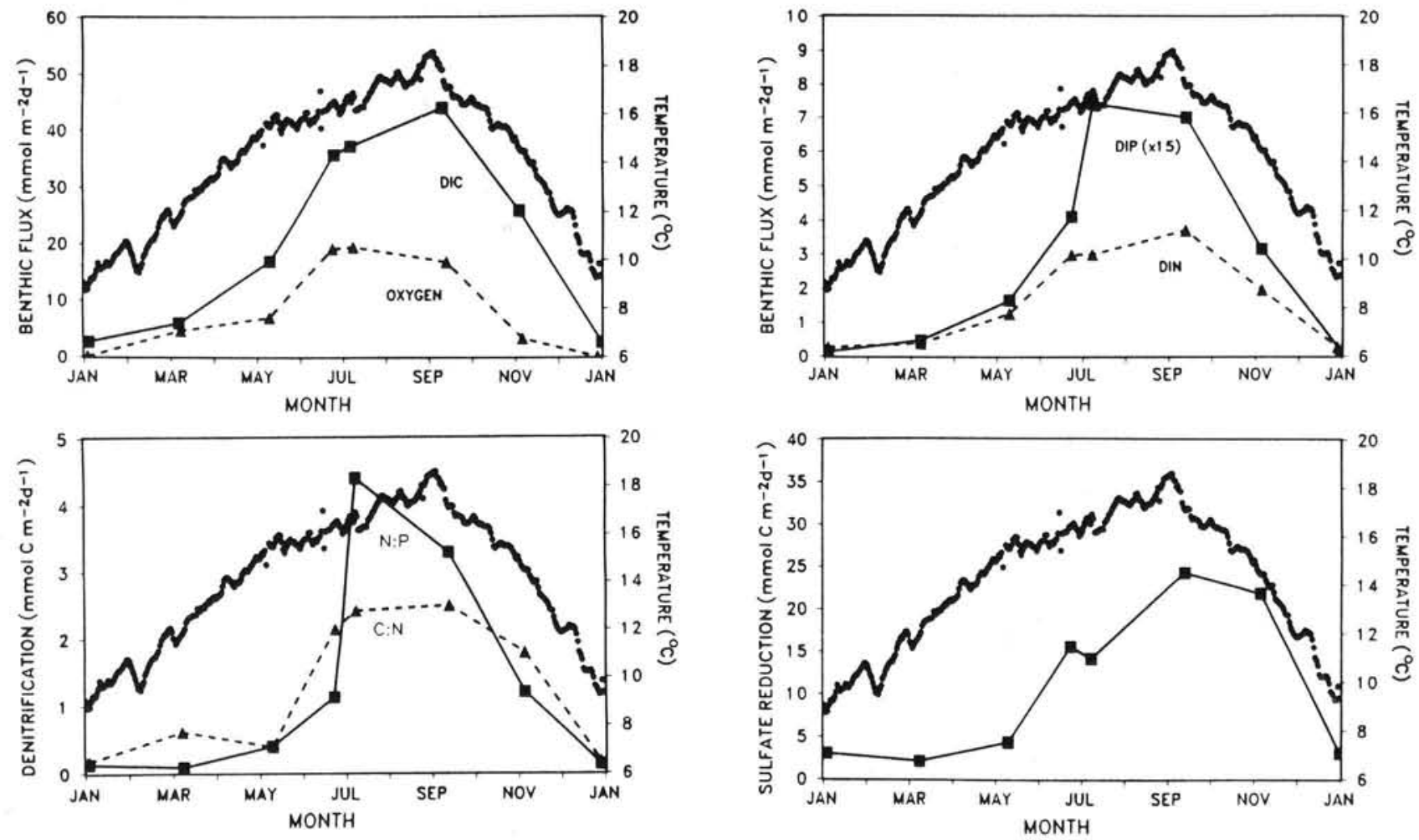

Fig. 4. Mean daily water temperature $(\bullet)$ and annualized mean benthic fluxes in Tomales Bay. Mean temperatures are calculated from data from 4 continuously recording thermographs spaced along the axis of the bay

sure results in alterations of nutrient fluxes from ambient oxic conditions. For example, Bulleid (1984) demonstrated a change in the relationship between oxygen and nutrient $(\mathrm{P}, \mathrm{N})$ fluxes as anoxic conditions were approached $\left(\mathrm{O}_{2}\right.$ concentrations less than $1.4 \mathrm{mg}$ $1^{-1}$ ). Fig. 6 is a histogram for our data showing the number of final endpoint measurements of $\mathrm{O}_{2}$ at intervals of $0.5 \mathrm{mg} \mathrm{l}^{-1}$ for the Tomales Bay benthic incubations. The 2 modes in the histogram generally reflect the winter endpoint measurements (about $7 \mathrm{mg} \mathrm{l}^{-1}$ ), and summer endpoints (about $3.5 \mathrm{mg} \mathrm{l}^{-1}$ ). Endpoint $\mathrm{O}_{2}$ values near the saturation values $\left(>8 \mathrm{mg} \mathrm{l}^{-1}\right)$ represent incubations in the southern end of the bay, where benthic photosynthesis occurred during the summer months. It can be seen that none of the endpoints was less than $1 \mathrm{mg} \mathrm{l}^{-1}$, and only 12 out of the 168 incubations had endpoints with concentrations less than $2.5 \mathrm{mg} \mathrm{l}^{-1}$. Thus, anoxic conditions were not an outcome of the benthic incubations, and it is not likely that reduced $\mathrm{O}_{2}$ concentrations affected nutrient fluxes.

Another verification of this conclusion is depicted in a scatter diagram of $\mathrm{O}_{2}$ flux versus DIC flux (Fig. 7). With the exception of several obvious outliers, the data points fall within 2 groupings. The majority of data lie within a band representing a linear proportionality between $\mathrm{O}_{2}$ uptake and DIC production. The $\mathrm{DIC} / \mathrm{O}_{2}$ slope of the relationship (ca -2) indicates that anaerobic metabolic processes are producing DIC without $\mathrm{O}_{2}$ uptake. The linearity of the distribution reveals that there are no apparent qualitative changes in the metabolic processes across the range of $\mathrm{O}_{2}$ flux. The smaller group, showing positive $\mathrm{O}_{2}$ flux (production), is composed of the measurements where benthic

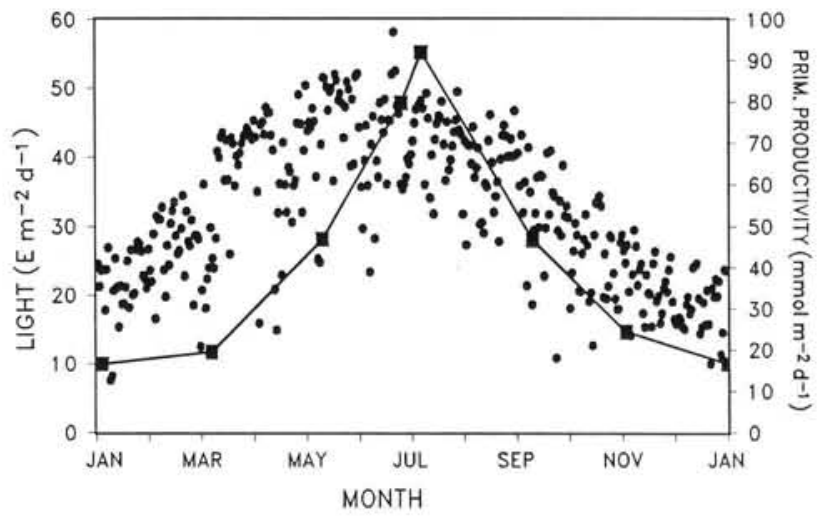

Fig. 5. Daily irradiance (light; $\bullet$ ) and annualized mean primary productivity (-) in Tomales Bay. Daily light measurements were calculated from data from 2 weather stations located on Tomales Bay 


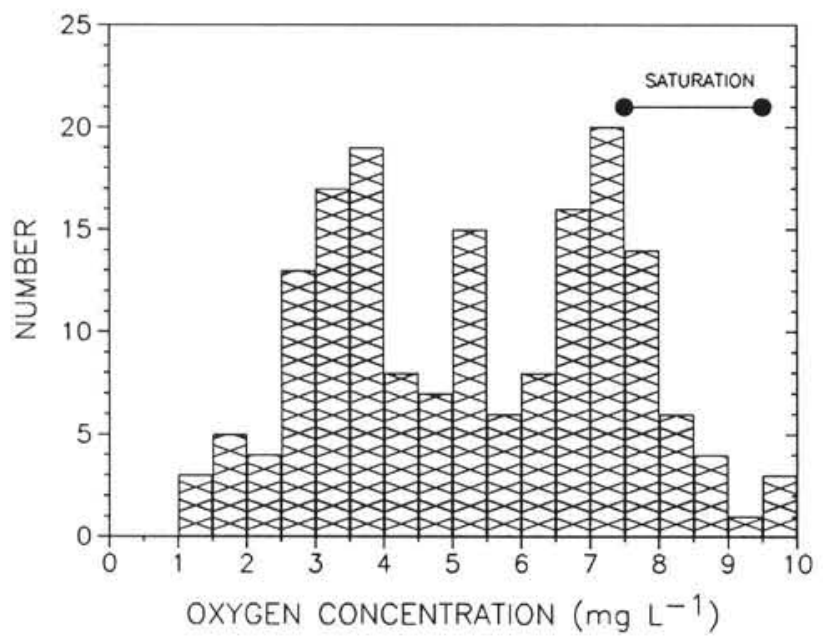

Fig. 6. Histogram showing the number of measurements of various $\mathrm{O}_{2}$ concentrations at the ends of benthic flux incubations, in $0.5 \mathrm{mg} \mathrm{l}^{-1}$ increments. The bar labeled 'saturation' indicates the range of $\mathrm{O}_{2}$ saturation at the temperatures and salinities encountered in Tomales Bay

photosynthesis was occurring in the southern end of the bay. Even with production of $\mathrm{O}_{2}$, DIC fluxes were also positive, indicating the occurrence of sulfate reduction within the sediment column.

\section{Tomales Bay in broader perspective}

Comparing benthic fluxes from Tomales Bay with similar data from other shallow marine environments allows us to position the metabolic performance characteristics of Tomales within a broader perspective. In addition, the metabolic performance of Tomales Bay can be used to assess conclusions based on component flux measurements in other marine environments.

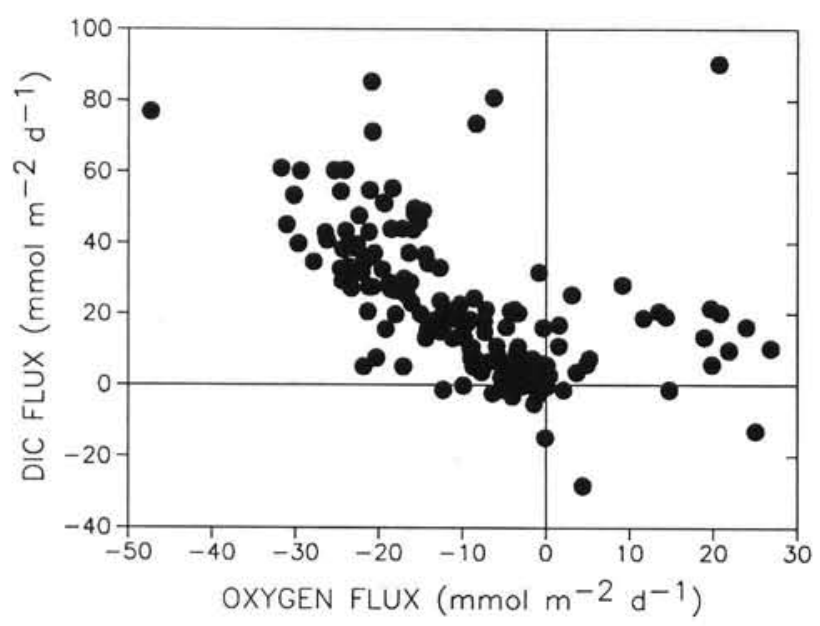

Fig, 7. Scatter diagram of benthic $\mathrm{O}_{2}$ fluxes vs DIC fluxes. Negative values indicate uptake by the sediments. Crossed lines indicate position of origin
A comparison of benthic community metabolism rates in 19 coastal systems shows a range of oxygen consumption from 0 to $83 \mathrm{mmol} \mathrm{m}^{-2} \mathrm{~d}^{-1}$, with a median of $23 \mathrm{mmol} \mathrm{m}^{-2} \mathrm{~d}^{-1}$ (summarized from van Es 1982 and Fisher et al. 1982). Most of these measurements are not annual averages; rather, data were largely collected during the summer months. While the annual mean benthic oxygen consumption in Tomales Bay is $9 \mathrm{mmol}$ $\mathrm{m}^{-2} \mathrm{~d}^{-1}$ (s.e. $=1.0$ ), the summer (June to September) average is about $17 \mathrm{mmol} \mathrm{m} \mathrm{m}^{-2} \mathrm{~d}^{-1}$, with a range of about 2 to 30 in individual measurements.

Considering benthic fluxes of $\mathrm{NH}_{4}{ }^{+}$, a comparison of measurements from 9 of the sites described above shows a range of 0 to $5.6 \mathrm{mmol} \mathrm{m} \mathrm{m}^{-2} \mathrm{~d}^{-1}$, with a median of $1.8 \mathrm{~m}^{-2} \mathrm{~d}^{-1}$. The annual bay-wide mean $\mathrm{NH}_{4}{ }^{+}$efflux at Tomales Bay is about $2.0 \mathrm{mmol} \mathrm{m}^{-2} \mathrm{~d}^{-1}$ (s.e. $=0.2$ ), while the summer average is about $3.2 \mathrm{mmol} \mathrm{m}^{-2} \mathrm{~d}^{-1}$. Based on these comparisons, it appears that Tomales falls on the low side of an 'average' benthic oxygen uptake rate, and on the high side of benthic $\mathrm{NH}_{4}{ }^{+}$ regeneration.

While only a few investigations have combined synchronous measurements of benthic fluxes and primary productivity, there are numerous locations where both sets of data have been collected independently. Nixon (1981) showed that a strong linear relationship exists between the amount of organic matter fixed plus that imported $(P+I)$, and the amount of organic matter respired on the bottom (BR) over an annual cycle. In 14 coastal marine systems, Nixon found that BR was about $24 \%$ of $P+I$ (i.e. the slope of the regression line, since the intercept is small), with $r^{2}=0.94$. The benthic remineralization rates used by Nixon to establish the relationship with primary productivity are based on converting oxygen uptake measurements to carbon using an RQ $\left(-\Delta \mathrm{CO}_{2} / \Delta \mathrm{O}_{2}\right)$ of 1 .

When primary productivity and benthic oxygen flux from 8 more sites (summarized in Fisher et al. 1982), as well as the annual averages derived in the present study for Tomales Bay, are added to Nixon's data (plotted as oxygen uptake rather than benthic carbon metabolism in Fig. 8), the geometric mean regression still indicates that an average of about $24 \%$ of primary productivity is metabolized via aerobic benthic processes. However, with the additional sites, $\mathrm{r}^{2}$ for the relationship decreases to 0.75 .

Using DIC flux as a measure of benthic metabolism rather than $\mathrm{O}_{2}$ flux results in a somewhat different interpretation. Our DIC flux measurements in Tomales Bay indicate that about $25 \%$ of the $\mathrm{C}$ fixed by water column primary production is metabolized by the benthos. Using measured annual oxygen uptake rates, and assuming an RQ of 1, the percentage of primary productivity metabolized by sediment communities in Tomales Bay decreases to $15 \%$. For Tomales Bay, at 


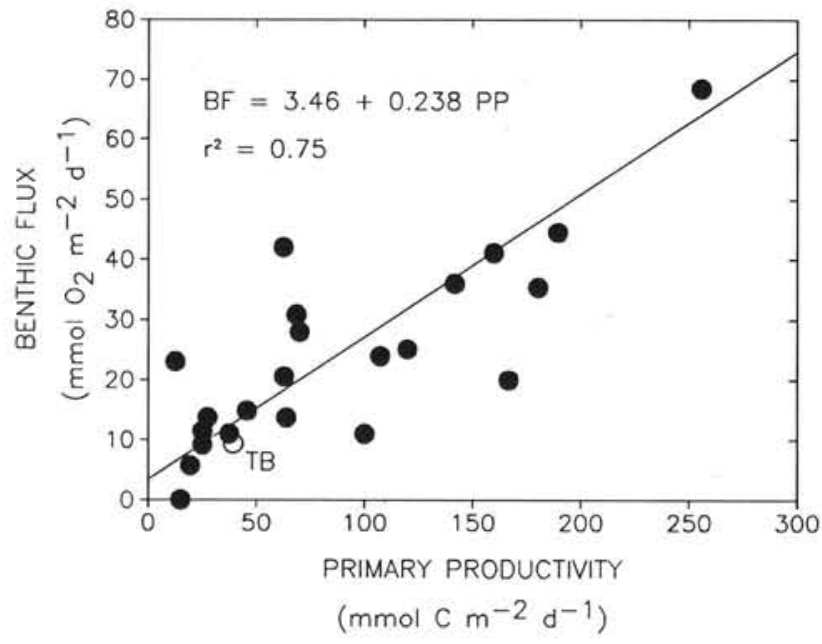

Fig, 8. Benthic flux of oxygen as a function of primary productivity from various coastal marine sites (modified from Nixon 1981). Data point near 'TB' represents Tomales Bay

least, using oxygen flux as a proxy for total benthic metabolism substantially underestimates total metabolism because of anaerobic DIC release.

\section{Comparison of net system and component fluxes}

Smith et al. (1991) and Smith \& Hollibaugh (1989) present a detailed critique of the validity of using a budgetary-stoichiometric approach for estimating system-level net metabolism. The budgetary-stoichiometric approach appears to be more robust than deriving net metabolism by the difference between 'direct' estimates of primary production and respiration.

Therefore, our purpose here is not to attempt to ascertain the net metabolic status of Tomales Bay by summation of component fluxes. Rather, we start with the conclusion that the bay, as a system, is net heterotrophic over an annual cycle. While hydrographically derived net fluxes provide this interpretation of ecosystem trophic status, there is no provision for partitioning metabolic function between the components that comprise the ecosystem. The discussion below reconciles net system performance with component fluxes in the benthos and water column.

Fig. 9 shows mean monthly carbon fluxes for benthic respiration (measured), water column productivity (estimated from a simple biomass-light algorithm), water column respiration (calculated by subtraction to balance the terms), and the mean annual metabolic system flux (calculated from a hydrographic mass balance model). It can be seen that as primary production rises in the summer months and decreases in fall, water column respiration correspondingly rises and falls. Benthic respiration continues to rise, however, in the months following the peak in primary productivity. The lag in peak benthic respiration results in a crossover with respect to water column respiration. Benthic respiration dominates metabolic turnover of particulate material in fall, while water column respiration dominates in spring and summer.

Examination of the relationships between environmental variables and metabolic fluxes provides some substantiation for the mechanism of the observed crossover. Light and primary productivity are essentially symmetrical over the annual cycle (Fig. 5). It must be mentioned, however, that this relationship is somewhat forced, as primary production is calculated with solar radiation as one of the variables (Cole 1989). Peak temperature and peak benthic flux coincide in September; this relationship is determined from independently derived data. In addition, the asymmetry of temperature and benthic flux curves (steeper drop in fall compared to the increase in spring-summer) is closely matched (Fig. 4).

It appears that during late winter and spring increasing light results in increasing water column primary productivity, followed closely by increasing water column respiration. However, during this period there is little delivery of newly metabolized organic material to the benthos, and small quantities of 'left-over' organic material from the previous summer are available to fuel benthic metabolism. Hence, there is the observed pattern of low benthic metabolism in spring primarily limited by the supply of labile organic material, and secondarily controlled by temperature. Essentially these conclusions have been reached by other authors (e.g. Hale 1975, Hargrave 1978, Nixon 1981).

Fallout of water column particulate material during summer results in peak benthic metabolism through

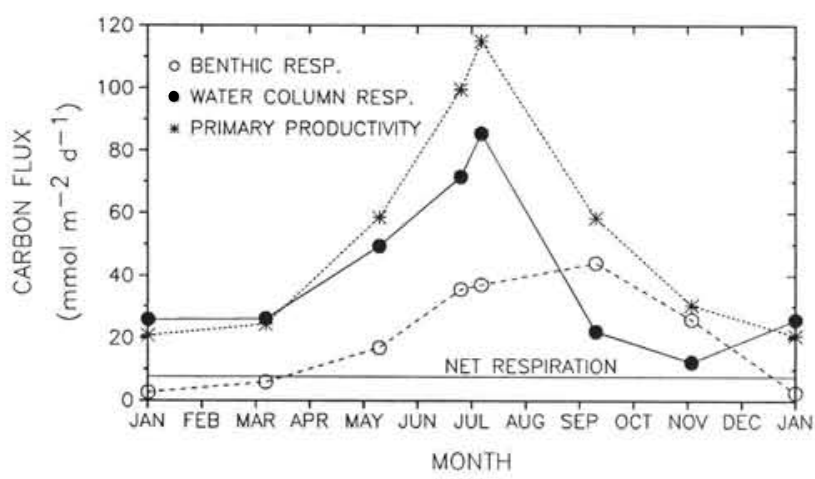

Fig. 9. Annualized mean carbon fluxes of various components of Tomales Bay system. Net system respiratory flux of $8 \mathrm{mmol}$ $\mathrm{m}^{-2} \mathrm{~d}^{-1}$ is from Smith et al. (1991). Primary productivity is the sum of water column and benthic productivity. Water column respiration is calculated by balancing the terms. Note "crossover' of benthic and water column respiration in late summer 
fall. The crossover with respect to benthic and water column respiration appears to be a consequence of lower particulate loads in the water column, along with abundant amounts of labile organics available to the benthos.

Seitzinger (1988) summarizes literature data on denitrification in various aquatic ecosystems. The median rate for 12 marine sites in which benthic denitrification has been measured is $1.8 \mathrm{mmol} \mathrm{m}^{-2} \mathrm{~d}^{-1}$. The system-wide value for Tomales Bay, derived by Smith et al. (1991), is $3.1 \mathrm{mmol} \mathrm{m}^{-2} \mathrm{~d}^{-1}$. The contribution of denitrification from Tomales sediment communities, calculated from benthic fluxes, is $1.25 \mathrm{mmol}$ $\mathrm{m}^{-2} \mathrm{~d}^{-1}$, about $60 \%$ below the rate derived from the bay-wide budget. This may represent an analytical artifact, or a bias from locating benthic metabolism stations away from areas of peak denitrification. As a comparison of 2 sets of independently derived numbers, we consider the agreement satisfactory. We suggest that estimating benthic denitrification rates from the stoichiometry of benthic respiration reactions may provide an alternative (or supplement) to more conventional bioassay techniques. Ongoing research in Tomales to measure denitrification in various microenvironments will provide an interesting comparison with the stoichiometric calculations.

A similar stoichiometric comparison can be made for the sulfate reduction component of anaerobic metabolism, specifically the production of mineral sulfides. The overall stoichiometry of $\mathrm{SO}_{4}^{2-}$ reduction to carbon oxidation $\left(\mathrm{HCO}_{3}{ }^{-}\right)$is $\mathrm{C}: \mathrm{S}=2$ (Aller \& Yingst 1980). Moreover, $\mathrm{SO}_{4}{ }^{2-}$ reduction increases alkalinity by about 1 equivalent for each mole of $\mathrm{CH}_{2} \mathrm{O}$ oxidized:

$$
2 \mathrm{CH}_{2} \mathrm{O}+\mathrm{SO}_{4}{ }^{2-} \rightarrow 2 \mathrm{HCO}_{3}^{-}+\mathrm{HS}^{-}+\mathrm{H}^{+}
$$

The bay-wide mean benthic TA flux, corrected for nutrient fluxes, is about $7 \mathrm{mmol} \mathrm{m} \mathrm{m}^{-2} \mathrm{~d}^{-1}$. The $\mathrm{C}$ flux of $7 \mathrm{mmol} \mathrm{m} \mathrm{m}^{-2} \mathrm{~d}^{-1}$ associated with TA flux results in the reduction of $3.5 \mathrm{mmol} \mathrm{SO}_{4}^{2-} \mathrm{m}^{-2} \mathrm{~d}^{-1}$ to $\mathrm{HS}^{-}$. Burial of $3.5 \mathrm{mmol} \mathrm{HS} \mathrm{m}^{-2} \mathrm{~d}^{-1}$ as pyrite $\left(\mathrm{FeS}_{2}\right)$ could yield a pyrite production rate of $1.75 \mathrm{mmol}(210 \mathrm{mg}) \mathrm{m}^{-2} \mathrm{~d}^{-1}$, or ca $77 \mathrm{~g} \mathrm{~m}^{-2} \mathrm{yr}^{-1}$.

The bay-wide sedimentation rate determined from changes in bathymetry between 1860 and 1957 is estimated at $8 \mathrm{~mm} \mathrm{yr}^{-1}$, or about $12 \mathrm{~kg}$ sediment $\mathrm{m}^{-2} \mathrm{yr}^{-1}$ (based on sediment bulk density of $1.5 \mathrm{~g} \mathrm{~cm}^{-3}$ ). Thus, if the total alkalinity flux is a result of precipitation of pyrite produced in sulfate reduction, about $0.6 \%$ of the sediment should be composed of pyrite.

Analysis of 11 sediment samples using Mossbauer spectroscopy for iron speciation and bulk elemental analysis by atomic emission (ICP/AES) revealed that percent $\mathrm{Fe}^{2+}$ by weight is $1 \%$ (s.e. $=0.1$ ) in Tomales Bay sediments. Similar analyses of 9 sediment samples from streams that empty into Tomales Bay revealed percent $\mathrm{Fe}^{2+}$ by weight to be $0.6 \%$ (s.e. $=0.1$ ). If all of the excess $\mathrm{Fe}^{2+}$ is pyrite, the net pyrite formation in the bay equals about $0.8 \%$ of the sediment mass. This estimate is in close agreement with the predicted value of $0.6 \%$ based on stoichiometric calculations utilizing TA fluxes.

The net sulfate reduction derived by the hydrographic model is $5.1 \mathrm{mmol} \mathrm{C}$ oxidation $\mathrm{m}^{-2} \mathrm{~d}^{-1}$ (or $2.6 \mathrm{mmol} \mathrm{SO}_{4}{ }^{2-}$ reduction) (Smith et al. 1991). Benthic flux measurements suggest about $7 \mathrm{mmol} \mathrm{C} \mathrm{m}{ }^{-2} \mathrm{~d}^{-1}$ is consumed by sulfate reduction to $\mathrm{HS}^{-}$, which is not reoxidized. While the estimate from the benthic fluxes is about 3 times larger than the net system estimate, we feel that the estimates are comparable, considering the variability associated with the benthic fluxes. For example, TA flux varies 4 -fold among the 3 benthic flux stations.

In addition, the sulfate reduction rates for Tomales Bay do not appear to be anomalous for marine sediments. Reeburgh (1983) reports the median sulfate reduction rate derived by assay techniques for marine sediments from 7 sites to be about $25 \mathrm{mmol} \mathrm{m} \mathrm{m}^{-2} \mathrm{~d}^{-1}$, while Jørgensen \& Sørensen (1985) report a mean rate of $14 \mathrm{mmol} \mathrm{m} \mathrm{m}^{-2} \mathrm{~d}^{-1}$ in estuarine sediments over an annual cycle. Our estimates, which are based only on measurements of benthic fluxes of TA, appear to be consistent with other estimates based on direct measurements of $\mathrm{SO}_{4}{ }^{2-}$ flux. Typically, sulfide burial is much less than half of total sulfate reduction (Berner 1989).

In summary, our 2-pronged approach of comparing component and system-level fluxes appears to be a useful procedure to assess the metabolic functioning of a hydrographically simple temperate estuary. Our methods involve routine field techniques that are efficient with respect to time, effort and output. Calculation of other components (e.g. water column respiration, denitrification) allows us to reconcile partitioning of component fluxes with a minimum of effort. While many of our 'reconciliations' to close the budgets do not match perfectly, they agree reasonably well within the envelope of variability that is inherent in the complex of environments that comprise Tomales Bay. For example, we can close the metabolic carbon budget for the sediments by summing the component fluxes of aerobic oxidation, denitrification, and sulfate reduction to within $15 \%$ of the measured DIC flux. Even if all component fluxes were measured directly, it is unlikely that net metabolism could be determined by summing the component fluxes. Variability associated with methodology, and with the multitude of microenvironments, precludes an accurate determination of small deviations from zero.

A final caveat should be given concerning our results to date. The 2 annual cycles during which data were 
collected were atypically dry years, with only about $30 \%$ of mean annual runoff. As such, terrigenous organic material delivery to the bay was below average', and might have caused our flux estimates to reflect a metabolic performance that was vastly different from that in normal, or in anomalously wet, years. Ongoing research in Tomales Bay is aimed at addressing these considerations.

Acknowledgements. This research was funded by National Science Foundation Grant numbers OCE-8613647, OCE8816709, OCE-8914833 (awarded to S.V.S.), and OCE-8914921 (awarded to J.T.H.). We thank G. Tribble, M. Atkinson, L. and M. McGahan for assistance in the field, and T. Walsh for analytical assistance. The Tiburon Center of Environmental Studies (TCES) provided a boat. K. Chave and M. Atkinson reviewed the manuscript, and provided helpful comments.

\section{LITERATURE CITED}

Aller, R. C., Yingst, J. Y. (1980). Relationships between microbial distributions and the anaerobic decomposition of organic matter in surface sediments of Long Island Sound, U.S.A. Mar. Biol. 56: 29-42

Atkinson, M. J., Grigg, R. W. (1984). Model of a coral reef ecosystem. 2. Gross and net benthic primary production at French Frigate Shoals, Hawaii. Coral Reefs 3: 13-22

Atkinson, M. J., Smith, S. V. (1983). C:N:P ratios of benthic marine plants. Limnol. Oceanogr. 28: 568-574

Berner, R. A. (1989). Biogeochemical cycles of carbon and sulfur and their effects on atmospheric oxygen over phanerozoic time. Palaeogeogr. Palaeolim. Palaeoecol. (Global and Planetary Change Section) 75: 97-122

Boynton, W. R., Kemp, W. M (1985). Nutrient regeneration and oxygen consumption by sediments along an estuarine salinity gradient. Mar. Ecol. Prog. Ser. 23: 45-55

Bulleid, N. C. (1984). Deoxygenation and remineralization above the sediment-water interface; an in-situ experimental study. Estuar. coast. Shelf Sci. 19: 15-25

Cole, B. E. (1989). Temporal and spatial patterns of phytoplankton production in Tomales Bay, California. estuar. coast. Shelf Sci. 28: 103-115

Fisher, T. R., Carlson, P. R., Barber, R. T. (1982). Sediment nutrient regeneration in three North Carolina estuaries. Estuar. coast. Shelf Sci. 14: 101-116

Hale, S. S. (1975). The roles of benthic communities in the nitrogen and phosphorus cycles of an estuary. Recent Adv. estuar. Res. 1: 291-308

Hargrave, B. T. (1978). Seasonal changes in oxygen uptake by settled particulate matter and sediments in a marine bay. J. Fish. Res. Bd Can. 35: 1621-1628

Hollibaugh, J. T., Cole, B. E., Dollar, S. J., Hagar, S. W., Vink,

This article was presented by K. R. Tenore, Solomons, Maryland, USA
S. M.. Kimmerer. W. J., Obrebski, S., Smith, S. V., Valentino, M., Walsh, T. W. (1988). Tomales Bay, California: a macrocosm for examining biogeochemical coupling at the land-sea interface. Eos 69: 843-845

Hopkinson, C. S. (1985). Shallow-water benthic and pelagic metabolism: evidence of heterotrophy in the nearshore Georgia Bight. Mar. Biol. 87: 19-32

Jørgensen, B. B., Sørensen, J. (1985). Seasonal cycles of $\mathrm{O}_{2}$, $\mathrm{NO}_{3}{ }^{-}$and $\mathrm{SO}_{4}{ }^{2-}$ reduction in estuarine sediments: the significance of $\mathrm{NO}_{3}{ }^{-}$reduction maximum in spring. Mar. Ecol. Prog. Ser. 24: 65-74

Nixon, S. W. (1981). Remineralization and nutrient cycling in coastal marine ecosystems. In: Nielson, B. J., Cronin, L. E. (eds.) Estuaries and nutrients. Humana Press, Clifton, NJ, p. $111-138$

Parsons, T. R., Maita, Y., Lalli, C. M. (1984). A manual of chemical and biological methods for seawater analysis. Pergamon Press, Oxford

Reeburgh, W. S. (1983). Rates of biogeochemical processes in anoxic sediments. Ann. Rev. Earth planet. Sci. 11: 269-298

Rizzo, W. M. (1990). Nutrient exchanges between the water column and a subtidal benthic microalgal community. Estuaries 13: 219-226

Rowe, G. T., Smith, S., Falkowski, P., Whitledge, T., Theroux, R., Phoel, W., Ducklow, H. (1986). Do continental shelves export organic matter? Nature, Lond. 324: 559-561

SAS Institute (1988). SAS/STAT User's Guide, Release 6.03 Edition. SAS Institute, Inc. Cary, NC

Seitzinger, S. P. (1988). Denitrification in freshwater and coastal marine ecosystems: ecological and geochemical significance. Limnol. Oceanogr. 33: 702-724

Seitzinger, S. P., Nixon, S. W., Pilson, M. E. (1984). Denitrification and nitrous oxide production in a coastal marine ecosystem. Limnol. Oceanogr. 29: 73-83

Seitzinger, S. P., Nixon, S. W., Pilson, M. E., Burke, S. (1980). Denitrification and $\mathrm{N}_{2} \mathrm{O}$ production in near-shore marine sediments. Geochim. cosmochim. Acta 44: 1853-1860

Smith, S. V. and co-authors (1987). Stoichiometry of C, N, P, and $\mathrm{Si}$ fluxes in a temperate-climate embayment. J. mar. Res. 45: 427-460

Smith, S. V., Hollibaugh, J. T. (1989). Carbon-controlled nitrogen cycling in a marine 'macrocosm': an ecosystem-scale model for managing cultural eutrophication. Mar. Ecol. Prog. Ser. 52: 103-109

Smith, S. V., Hollibaugh, J. T., Dollar, S. J., Vink, S. (1989). Tomales Bay, California: a case for carbon-controlled nitrogen cycling. Limnol. Oceanogr. 34: 37-52

Smith, S. V., Hollibaugh, J. T., Dollar, S. J., Vink, S. (1991). Tomales Bay net metabolism: nonconservative C-N-P stoichiometry and ecosystem heterotrophy at the land-sea interface. Estuar. coast. Shelf Sci. 33: 223-257

Technicon Industrial Systems (1973). Technicon industrial methods for the analysis of seawater. Tarrytown, New York

van Es, F. B. (1982). Community metabolism of intertidal flats in the Ems-Dollard Estuary. Mar. Biol. 66: 95-108

Manuscript first received: March 19, 1991

Revised version accepted: October 10, 1991 